\title{
MASLAHAH DALAM PERSPEKTIF HUKIIM ISLAM
}

\author{
Oleh : SALMA
}

Kata maslahah berarti kepentingan, manfaat yang jika digunakan bersama dengan kata mursalah berarti bermakna kepentingan yang tidak terbatas, tidak terikat, atau kepentingan yang diputuskan secara bebas Metode maslahah mursalah muncul sebagai pemahaman mendasar tentang konsep bahwa syari at ditujukan untuk kepentingan masyarakat dan berfungsi untuk memberikan kemanfaatan dan mencegah kemudaratan. Para ulama ushul fikih membagi maslahah ke dalam tiga kategori yaitu: I maslahah berdasarkan segi perubahan maslahax, terdiri dari al-maslahah assabitah dan al-mastahah al-muiagayyirah 2. Maslahah berdasarkan keberadaan maslahat menurut syara', terdiri dari : al-maslahah al-mu'tabarah, al-maslahah al-mulgah, dan al-maslahah almursalah. 3. Maslahah berdasarkan segi kualitas dan kepent'ngan kemaslahatan, terdiri dari: almaslahah al-dharuriyyah, al-maslahah al-hajiyyah dan al-maslahah al-tahsiniyah.

\section{PENDAHULUAN}

\section{A. Latar Belakang Masalah}

Syari'ah Islam yang dianut oleh umat manusia (Islam) berawal dari datangnya Muhammad saw. Beliau adalah pembawa risalah terakhir dari ajaran Ilahi, yang merupakan lanjutan dari risalah-risalah yang pernah ada sebelumnya. Syari'at yang diwahyukan oleh Allah itu dibawa oleh beliau untuk segenap umat manusia agar dijadikan pedoman dalam hidup dan kehidupannya. ${ }^{1}$

Islam adalah agama yang memberi pedoman hidup kepada manusia secara menyeluruh, meliputi segala aspek kehidupannya menuju tercapainya kebahagiaan hidup rohani dan jasmani, baik dalam kehidupan individunya maupun dalam kehidupan masyarakatnya Secara umum, tujuan pencipta hukum (Syar'i) dalam menetapkan hukum-hukumnya adalah untuk kemaslahatan dan kepentingan serta kebahagiaan manusia seluruhnya, baik kebahagiaan di dunia yang fam (sementara) ini, maupun akhirat yang haqa (kekal) kelak. Tujuan hukum Islam yang demikian itu dapat kita tangkap antara lain dari firman Allah dalam QS. al-Anbiya' (21); 107 dan QS. al-Baqarah (2): 201-202. ${ }^{2}$

Dari uraian di atas memberi gambaran bahwa manusia sangat tergantung dan membutuhkan syari'ah sehingga syari'ah menjadi sangat urgen bagi kehidupan umat manusia dengan tujuan agar bisa dijadikan pegangan dalam kehidupan di dunia menuju kehidupan yang abadi di akhirat kelak

\section{B Rumusan dan Balasan Masalah}

Dari apa yang telah diuraikan di atas, maka yang menjadi sub adalah sebagai berikut:

1 Apa pengertian al-Maslahah dalam perspektif hukum Islam?

2 Berapa macam pembagian al-Maslahah dalam hukum Islam menurut

\footnotetext{
${ }^{1}$ Hamka Haq, Falsafat Ushul Fiqh (Makassar: Yayasan al-Ahkam,1998), h.1.

${ }^{2}$ Suparman Uvnan, Hukum Islam, Asas-Asas dan Pengantar, Studi Hukum Islam dalam Tata Hukum Indonesia (Cet. I; Jakarta : Gaya Media Pratama, 2001), h. 66.
} 


\section{PEMBAHASAN}

\section{A. Pengertian al-Maslahah}

Maslahah, secara etimologi adalah kata tunggal dari al-masalih, yang searti dengan kata salah, yaitu " mendatangkan kebaikan Terkadang digunakan juga istilah lain yaitu al-islislah yang berarti " mencari kebaikan " Tak jarang kata maslahah atau istislah ini disertai dengan kata al-mu nasib yang berarti "hal-hal yang cocok, sesuai dan tepat penggunaannya. ${ }^{3}$ Dari beberapa arti ini dapat diambil suatu pemahaman bahwa setiap sesuatu, apa saja, yang mengandung manfaat di dalamnya baik untuk memperoleh kemanfaatan, kebaikan, maupun untuk menolak kemudaratan, maka semua itu disebut dengan maslahah.

Dalam konteks kajian ilmu ushul al-fiqh, kata tersebut menjadi sebuah istilah teknis, yang berarti " berbagai manfaat yang dimaksudkan Syari' dalam penetapan hukum bagi hamba-hambaNya, yang mencakup tujuan untuk memelihara agama, jiwa, akal, keturunan, dan harta kekayaan, serta mencegah hal-hal yang dapat mengakibatkan luputnya seseorang dari kelima kepentingan tersebut. ${ }^{4}$

Maslahah merupakan salah satu metode analisa yang dipakai oleh ulama ushul dalam menetapkan hukum (istinbat) yang persoalannya tidak diatur secara eksplisit dalam al-Qur'an dan al-Hadis Hanya saja metode ini lebih menekankan pada aspek maslahat secara langsung

Maslahah mursalah dalam pengertiannya dapat dimaknai dengan sesuatu yang mutlak Menurut istilah para ahli ilmu ushul fiqhi ialah suatu kemaslahatan, di mana syari'ah tidak mensyariatkan suatu hukum untuk merealisir kemaslahatan itu dan tidak ada dalil yang menunjukkan atas pengakuan dan penolakannya. ${ }^{5}$

Maslahah mursalah biasa ditemukan dengan melalui metode islislah, dan ini menjpakan dasar (sumber) hukum Islam Menurut istilah para fuqaha, islislah adalah hukum (yang ditetapkan) karena tuntutan maslahat yang tidak didukung maupun diabaikan oleh dalil khusus, tetapi sesuai dengan maqashid al-Syari'ah al-Ammali (tujuan umum hukum Islam). Istislah merupakan jalan yang ditempuh hukum Islam untuk menerapkan kaidah-kaidah dan perintah-perintahnya terhadap berbagai peristiwa baru yang tidak ada nashnya. juga menjadi jalan dalam menetapkan aturan yang harus ada dalam kehidupan umat manusia, agar sesuai dengan maqashid al-Syari 'ah al-Ammah, dalam rangka menarik kemaslahatan, menolak kemafsadatan dan menegakkan kehidupan sempurna mungkin. ${ }^{6}$

Maslahah mursalah adalah pengertian maslahat secara umum, yaitu yang dapat menarik manfaat dan menolak mudarat, serta yang direalisasikan oleh syari at Islam dalam bentuk umum. Nash-nash pokok ajaran Islam telah menetapkan kewajiban memelihara kemaslahatan dan memperhatikannya ketika mengatur berbagai aspek kehidupan. Pembuat syara' (Allah swt dan Rasul-Nya) tidak menentukan bentuk-bentuk dan macam-macam maslahat, sehingga maslahat seperti ini disebut dengan mursalah, yaitu mutlak tidak terbatas

\footnotetext{
${ }^{3}$ H.M.Hasbi Umar, Nalar Fiqh Kontemporer (Cet. I; Jakarta: Gaung Persada Press, 2007), h.112.

${ }^{4}$ Ibid

${ }^{5}$ Abd. Wahab Khallaf, Vm Ushul al-Fiqhi (Jakarta : Majelis ATa li Indonesiyyin li al-Dakwah al-lslamiyah, 1973),h. 116.

${ }^{6}$ Mustafa Ahmad al-Zarqa', Al-lstislah wa al-Masai ih al-Mursalah fi Syari'ah al-lslamiyyah wa Ushul Fiqh, diterjemahkan oleh Ade Dedi Rohayana, M.Ag. dengan judul Hukum Islam dan Perubahan Sosial (Studi Komparatif Delapan Mazhab Fiqhi) (Cet I; Jakarta : Riora Cipta, 2000), h. 33.
} 
Apabila sebuah maslahat didukung oleh nash, seperti menuliskan al-Qur'an supaya tidak hilang, mengajar membaca dan menulis, atau terdapat nash yang mendukungnya, seperti kewajiban mengajarkan dan menyebarkan ilmu, perintah mengajarkan segala kebaikan yang diperintahkan syara' dan larangan mengerjakan segala macam kemungkaran yang dilarang syara', maka maslahah semacam ini disebut maslahah mansus (maslahah yang ada nashnya), maslahah jenis ini tidak termasuk maslahah mursalah Hukum maslahah mansus ditetapkan oleh nash bukan oleh metode istislah

Istislah merupakan cara atau metodeistinbhat yang diperselisihkan para Imam Mujtahid Di antara mereka, ada yang mengakuinya dan ada pula yang menolaknya

\section{B Macam-macam Pembagian Maslahah}

Telah dijelaskan di atas, bahwa Syari'at Islam berorientasi pada kemanfaatan dan menitikberatkan keserasian hukum untuk memajukan kemaslahatan Premis dasarnya adalah bahwa hukum harus melayani kepentingan masyarakat. Kemaslahatan atau kepentingan itu dapat dikategorikan ke dalam tiga kategori, yaitu :

1. Maslahah berdasarkan segi perubahan maslahat;

2 Maslahah berdasarkan keberadaan maslahat menurut syara";

3 Maslahah berdasarkan segi kualitas dan kepentingan kemaslahatan

Berikut ini penulis akan memapaparkan masing-masing pembagian kategori tersebut yaitu sebagai berikut:

\section{Maslahah berdasarkan segi perubahan maslahat}

Menurut Mustafa asy-Syalabi (guni besar usul fiqh Universitas al-Azhar, Cairo), terdapat dua bentuk maslahat berdasarkan segi perubahan maslahat Pertama, al-maslahah as-sabitah.yaitu kemaslahatan yang bersifat tetap, tidak berubah sampai akhir zaman Misalnya, berbagai kewajiban ibadah seperti shalat, puasa, zakat, dan haji. Kedua, al-maslahah al-mutagayyirah, yaitu kemaslahatan yang berubah-ubah sesuai dengan perubahan tempat, waktu, dan subjek hukum Kemaslahatan seperti ini berkaitan dengan permasalahan muamalah dan adat kebiasaan, seperti dalam masalah makanan yang berbeda-beda antara satu daerah dan daerah lainnya Perlunya pembagian ini, menurut Mustafa asy-Syalabi dimaksudkan untuk memberikan batasan kemaslahatan yang bisa berubah dan yang tidak berubah. ${ }^{7}$

2. Maslahah berdasarkan keberadaan maslahah menurut syara'.

Maslahat semacam ini menurut Mustafa asy-Syalabi membaginya kepada tiga macam yaitu : 1. al-maslahah al-mu tabarah, 2. al-maslahah al-mulgah, 3. al-maslahah al-mursalah.

a AI-Maslahah al-Mu tabarah

${ }^{7}$ Abdul Azis Dahlan et al, Ensiklopedi Hukum Islam (Cet III; Jakarta : Ichtiar Baru Van Hoeve, 1999), h. 1145. 
Al-maslahah al-mu tabarah adalah kemaslahatan yang mendapat dukungan oleh syara'. baik jenis maupun bentuknya Artinya, adanya dalil khusus yang menjadi dasar bentuk dan jenis kemaslahatan tersebut Misalnya tentang hukuman atas orang yang meminum minuman keras Bentuk hukuman bagi orang yang meminum minuman keras yang terdapat dalam hadis Rasulullah Saw dipahami secara berlainan oleh ulama fikih Hal ini disebabkan perbedaan alat pemukul yang digunakan Nabi Saw ketika melaksanakan hukuman bagi orang yang meminum minuman keras Ada hadis yang menunjukkan bahwa alat yang digunakan Rasulullah Saw adalah sandal atau alas kakinya sebanyak 40 kali (HR. Ahmad bin Hanbal dan al-Baihaqi), sementara itu hadis lain menjelaskan bahwa alat pemukulnya adalah pelepah pohon kurma, juga sebanyak 40 kali (HR Bukhari dan Muslim). Karenanya setelah Umar bin Khattab (sahabat Nabi Saw) bermusyawarah dengan para sahabat lain, menetapkan hukuman dera bagi orang yang meminum minuman keras tersebut sebanyak 80 kali. Ia mengkiaskan orang yang meminum minuman keras kepada orang yang menuduh orang lain berbuat zina Logikanya adalah seseorang yang meminum minuman keras apabila mabuk bicaranya tidak bisa terkontrol dan diduga keras akan menuduh orang lain berbuat zina Hukuman untuk seseorang yang menuduh orang lain berbuat zina adalah 80 kali dera yaitu QS An-Nuur (24):

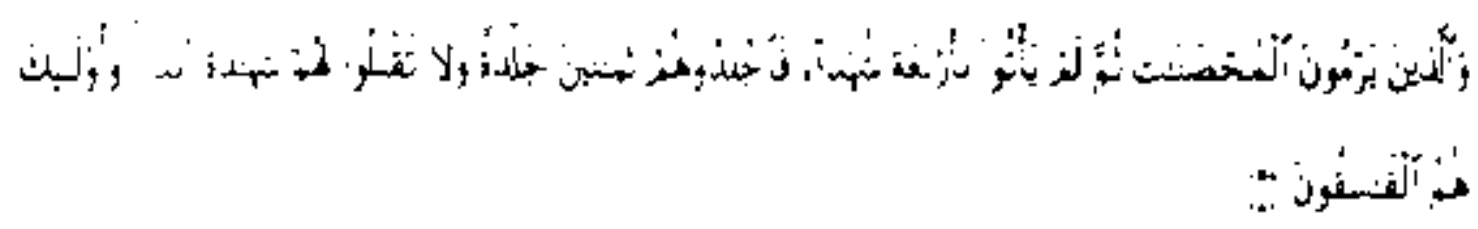

Terjemahnya

Dan orang-orang yang menuduh wanita-wanita yang baik-baik (berbuat zina) dan mereka tidak mendatangkan empat orang saksi, maka deralah mereka (yang menuduh itu) delapanpuluh kali dera, dan janganlah kamu terima kesaksian mereka buat selama-lamanya Dan mereka itulah orang-orang yang fasik. ${ }^{8}$

Karena adanya dugaan keras menuduh orang lain berbuat zina akan muncul dari orang yang mabuk, maka Umar bin Khttab dan Ali bin Abi Talib mengatakan bahwa hukuman orang yang meminum minuman keras sama hukumnya dengan orang yang menuduh orang lain berbuat zina Menurut ulama usul fikih, cara analogi seperti ini termasuk kemaslahatan yang didukung oleh syara'. ${ }^{9}$ Kemaslahatan yang mendapat dukungan oleh syara. baik jenis maupun bentuknya disebut al-maslahah al-mu'iabarah. Menurut kesepakatan ulama, kemaslahatan seperti ini dapat dijadikan landasan hukum

\section{b Al-Maslahah al-Mulgah.}

Al-maslahah al-mulgah adalah kemaslahatan yang ditolak oleh syara' karena bertentangan dengan ketentuan syara' Misalnya, syara' menentukan bahwa orang yang melakukan hubungan seksual di siang hari dalam bulan Ramadhan dikenakan hukuman memerdekakan budak, atau puasa selama dua bulan berturut-turut, atau memberi makan bagi 60 orang fakir maiskin (HR Bukhari dan Muslim). Al-Lais bin Sa'ad, ahli fikih mazhab Maliki di Spanyol, menetapkan hukuman puasa dua

${ }^{8}$ Departemen Agama RI, Al-Qur'on dan Terjemahnya, (Jakarta : Yayasan Penyelenggara Penterjemah Al-Qur'an, 1984), h. 543- 
bulan berturut-turut bagi seseorang (penguasa Spanyol) yang melakukan hubungan seksual dengan istrinya di siang hari dalam bulan Ramadhan Ulama memandang hukum ini brtentangan dengan hadis Nabi Saw di atas. karena bentuk-bentuk hukuman itu harus diterapkan secara berurut Apabila tidak mampu memerdekakan budak, baru dikenakan hukuman puasa dua bulan berturut-turut Karenanya, ulama usul fikih memandang mendahulukan hukuman puasa dua bulan berturut-turut dari memerdekakan budak merupakan kemaslahatan yang bertentangan dengan kehendak syara', sehingga hukumnya batal (ditolak) syara'. Kemaslahatan seperti ini menurut kesepakatan ulama disebut al-maslahah al-mulgah. ${ }^{10}$

\section{c. Al-Maslahah al-Mursalah.}

Al-maslahah al-mursalah adalah kemaslahatan yang didukung oleh sekumpulan makna nash (ayat atau hadis), bukan oleh nash yang rinci Kemaslahatan yang keberadaannya tidak didukung syara' dan tidak pula dibatalkan (ditolak) syara' melalui dalil yang rinci Kemaslahatan dalam bentuk ini terbagi dua . yaitu kemaslahatan yang sama sekali tidak ada dukungan dari syara', baik secara rinci maupun secara umum, dan kemaslahatan yang tidak didukung oleh dalil syara' secara rinci, tetapi didukung oleh makna sejumlah nash Kemaslahatan yang pertama disebut sebagai almaslahah al-garibah ( kemaslahatan yang asing ),namun para ulama tidak dapat mengemukakan contohnya secara pasti Bahkan Imam asy-Syatibi mengatakan kemaslahatan seperti ini tidak ditemukan dalam praktek, sekalipun ada dalam teori Sedangkan kemaslahatan dalam bentuk kedua disebut al-maslahah al-mursalah Kemaslahatan ini didukung oleh sekumpulan makna nash (ayat atau hadis), bukan oleh nash yang rinci. ${ }^{11}$

Ulama usul fikih sepakat menyatakan bahwa al-maslahah al-mu'tabarah dapat dijadikan hujjah (alasan) dalam menetapkan hukum Islam Kemaslahatan seperti ini termasuk dalam metode kias Mereka juga sepakat menyatakan bahwa al-maslahah al-mulgah tidak dapat dijadikan landasan dalam menetapkan hukum Islam, demikian juga dengan al-maslahah al-garibah. karena tidak ditemukan dalam praktek Adapun terhadap kehujahan al-maslahah al-mursalah. pada prinsipnya jumhur ulama mazhab menerimanya sebagai salah satu alasan dalam menetapkan hukum syara', sekalipun dalam menetukan syarat, penerapan, dan penempatannya, mereka berbeda pendapat

3. Maslahah berdasarkan segi kualitas dan kepentingan kemaslahatan.

Para ahli usul fikih mengemukakan beberapa pembagian maslahat Berdasarkan segi kualitas dan kepentingan kemaslahatan, mereka membaginya dalam tiga bentuk sebagai berikut:

a. Al-Maslahah ai-Dharuriyyah

b. Al-Maslahah al-Hajiyyah

c. AI-Maslahah al-Tahsiniyyah ${ }^{12}$

${ }^{10}$ Ibid., h.1146
${ }^{11}$ ibid
${ }^{12}$ Abdul Azis Dahlan, et al. Ensiklopedia Hukum Islam (Cet. I; Jakarta : Ikhtiar Baru Van Hoeve,1984), h. 1109. 
a). Al-Maslahah al-Dharuriyyah yaitu kemaslahatan yang berhubungan dengan kebutuhan pokok umat manusia di dunia dan di akhirat Dengan kata lain Al-Maslahah al-Dharuriyyah (kebutuhan primer) adalah kebutuhan mendasar yang menyangkut mewujudkan dan melindungi eksistensi lima pokok yaitu : memelihara agama, memelihara jiwa, memelihara akal, memelihara keturunan, dan memelihara harta Menurut para ahli usul fikih, kelima kemaslahatan ini disebut al-masalih alkhamsah. Apabila kemaslahatan ini hilang, maka kehidupan manusia akan bisa hancur karenanya, dan tidak akan selamat baik di dunia maupun di akhirat Menurut al-Syathibiy, dari kelima hal ini adalah agama dan dunia dapat berjalan seimbang dan apabila dipelihara akan dapat memberi kebahagiaan bagi masyarakat dan pribadi. ${ }^{13}$

b). Al-Maslahah al-Hajiyyah yaitu kemaslahatan yang dibutuhkan dalam menyempurnakan kemaslahatan pokok atau mendasar sebelumnya yang berbentuk keringanan untuk mempertahankan dan memelihara kebutuhan dasar manusia Dengan kata lain, kebutuhan alHajiyyah ( kebutuhan sekunder), adalah suatu yang dibutuhkan bagi kehidupan manusia, akan tetapi tidak mencapai tingkat dharury Seandainya kebutuhan ini tidak terpenuhi dalam kehidupan manusia, tidak akan meniadakan atau merusak kehidupanitu sendiri, namun keberadaannya dibutuhkan untuk memberi kemudahan dalam kehidupannya. ${ }^{14}$

Adapun tujuan hajiyyah dari segi penetapan hukumnya, dikelompokkan menjadi tiga,yaitu:

1. Hal-hal yang disuruh syara', seperti mendirikan sekolah dalam hubungannya untuk menuntut ilmu, meningkatkan kualitas akal Mendirikan sekolah memang penting, namun seandainya sekolah tidak didirikan, tidaklah berarti tidak tercapai upaya mendapatkan ilmu, karena menuntut ilmu itu dapat dilaksanakan di luar sekolah. Karenanya kebutuhan akan sekolah berada pada tingkat hajiyyah. ${ }^{15}$

2. Hal yang dilarang oleh syara' melakukanya, menghindarkan secara tidak langsung pelanggaran pada salah satu unsur yang dharury Contoh, perbuatan zina berada pada tingkat dharury. Namun segala perbuatan yang menjurus kepada perbuatan zina itu juga dilarang, hal ini dimaksudkan untuk menutup pintu bagi terlaksananya larangan zina yang dharury, misalnya khahvat dan sebagainya

3. Segala bentuk kemudahan yang termasuk hukum ruksah (kemudahan) yang memberi kelapangan dalam kehidupan manusia Sebenarnya tidak ada rukhsah pun tidak akan hilang salah satu unsur dharury itu, tetapi manusia akan berada dalam kesempitan (kesulitan) Rukhsah ini berlaku dalam hukum ibadah seperti shalat musafir, dalam muamalat, seperti jual beli salam, dalam jinayat. seperti adanya maaf untuk membatalkan qishash bagi pembunuh, baik diganti dengan membayar diyat (denda) ataupun tanpa diyat sama sekali. ${ }^{16}$

c). Al-Maslahah al-Tahsiniyyah yaitu kemaslahatan yang sifatnya pelengkap berupa keleluasan yang dapat melengkapi keemaslahatan sebelumnya Dengan kata lain adalah sesuatu kebutuhan hidup yang sifatnya komplementer dan lebih menyempurnakan kesejahteraan hidup manusia

\footnotetext{
${ }^{13}$ ibid

${ }^{14}$ Amir Syarifuddin, Ushul Fiqh (Cet I; Jakarta : Logos Wacana Ilmu, 1999), h. 213.

${ }^{15}$ ibid

${ }^{16}$ lbid, h. 213-214.
} 
Jika kemaslahatan Tahsiniyyah ini tidak terpenuhi, maka kemaslahatan hidup manusia akan terasa kurang indah dan kurang nikmat, kendatipun tidak sampai menimbulkan kemelaratan dan kebinasaan hidup. ${ }^{17}$ Keberadaannya dikehendaki untuk kemuliaan akhlak dan kebaikan tata tertib pergaulan

Dari uraian di atas. dapatlah dipahami bahwa tujuan pokok syari'ah adalah kemaslahatan umat manusia dalam kehidupannya, yang meliputi lima unsure pokok yaitu : memelihara agama, memelihara jiwa. memelihara akal, memelihara keturunan dan memelihara harta benda Istilah populer di kalangan ulama ushul disebut al-masahh al-kham.sahKelima hal pokok ini harus dipelihara, dijaga dan diwujudkan agar memperoleh kebahagiaan hidup baik di dunia maupun di akhirat

Untuk memelihara, menjaga dan mewujudkan hukum pokok tersebut, para ahli ushul membagi kepada tiga kelompok kebutuhan sesuai dengan kualitas kebutuhan dan kepentingan kemaslahatannya. Ketiga kelompok kebutuhan tersebut meliputi kebutuhan yang bersifat dharuriyyah (primer), kebutuhan hajiyyah (sekunder) dan kebutuhan tahsiniyyah (pelengkap atau penyempurna).

\section{PENUTUP}

Berdasarkan uraian terdahulu maka panulis dapat mengambil beberapa kesimpulan, yaitu sebagai berikut:

1. Kata maslahah berarti kepentingan, manfaat yang jika digunakan bersama dengan kata mursalah berarti bermakna kepentingan yang tidak terbatas, tidak terikat, atau kepentingan yang diputuskan secara bebas Metode maslahah mursalah muncul sebagai pemahaman mendasar tentang konsep bahwa syari at ditujukan untuk kepentingan masyarakat dan berfungsi untuk memberikan kemanfaatan dan mencegah kemudaratan

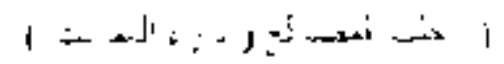

2 Para ulama ushul fikih membagi maslahah ke dalam tiga kategori yaitu: I maslahah berdasarkan segi perubahan maslahax, terdiri dari al-maslahah as-sabitah dan al-mastahah al-muiagayyirah 2. Maslahah berdasarkan keberadaan maslahat menurut syara', terdiri dari : al-maslahah almu'tabarah, al-maslahah al-mulgah, dan al-maslahah al-mursalah. 3. Maslahah berdasarkan segi kualitas dan kepent'ngan kemaslahatan, terdiri dari: al-maslahah al-dharuriyyah, al-maslahah alhajiyyah dan al-maslahah al-tahsiniyah.

\footnotetext{
${ }^{17}$ Hamka Haq, op. cit., h.76.
} 


\section{DAFTAR PUSTAKA}

Al-Our'an dan Terjemahnya

Ahmad al-Zarqa. Mustafa. Al-lstislah mi al-Masalih al-Mursalah fi Syariah al-Islamiyah wa Ushul fiqh ditrjemahkan oleh Adr Dedi Rohayana. M.Ag, dengan judul Hukum Islam dan Perubahan Sosial (Studi Kompratif Delapan Mazhab Fiqhi),Cet I, Jakarta, Riora Cipta, 2000.

Dahlan, Abdul Azis, et. al. Ensiklopedia Hukum Islam, Cet. 1, Jakarta, Ikhtiar Baru Van Hoeve, 1996

Dahlan. Abdul Azis., et. al. Ensiklopedi Hukum Islam, Cet. III, Jakarta, Ichtiar Baru Van Hoeve, 1999

Haq, Hamka, Falsafat Ushul Fiqh, Makassar. Yayasan al-Ahkam, 1998

Khallaf, Abdul Wahab. 'Ilm Ushul al-Fiqhi. Jakarta. Majelis A'la li Indonesivyin li al-Dakwah allslamiyah. 1973.

Syarifiiddin, Amir, Ushul al-Fiqh,Cet I, Jakarta, Logos Wacana Ilmu. 1999.

Umar, H M Hasbi, Nalar Fiqh Kontemporer, Cet 1. Jakarta. Gaung Persada Press, 2007

Usman. Suparman. Hukum Islam, Asas-asas dan Pengantar Studi Hukum Islam dan Tata Hukum Indonesia. Cet. 1, Jakarta, Gaya Media Pratama. 2001. 